\title{
Amino acid profile in Down's syndrome
}

\author{
H J Heggarty, R Ball, M Smith, M J Henderson
}

\begin{abstract}
Fasting plasma and urinary amino acid concentrations were studied under carefully controlled conditions in 22 children with Down's syndrome and in age matched controls. The only significant difference between the groups was a higher mean plasma lysine concentration in Down's syndrome patients compared to controls. (Arch Dis Child 1996; 74: 347-349)
\end{abstract}

Keywords: Down's syndrome, plasma amino acids, urine amino acids.

The late Professor Lejeune and his colleagues published a report in $1992^{1}$ showing that the concentrations of urinary and serum amino acids in patients with Down's syndrome differed from those of healthy controls. Their study covered a mixed age range and included many adults. It showed that plasma concentrations of cysteine and lysine were increased in patients with Down's syndrome and plasma serine decreased when compared to controls. The urine of the Down's syndrome patients also contained raised concentrations of tyrosine, methionine, cysteine, and methyl-histidine compared to controls. In the present study, all the patients were children below the age of 18 .

\section{Methods}

Twenty two children with Down's syndrome provided blood samples and 21 provided urine samples. The controls were healthy children of comparable age. Twenty controls provided urine samples and 18 provided blood samples.

None of the subjects was receiving any medication or special diets during the two weeks before sampling, all of which was done in the fasting state. Only two investigators collected the samples, many of which were obtained on early morning home visits to minimise inconvenience and stress to the families.

The amino acid analysis was carried out on a Biochrom 20 analyser, involving separation by ion exchange chromatography and post-column ninhydrin derivatisation and spectrophotometric deletion at 570 and $440 \mathrm{~nm}$.

\section{Results}

Figure 1 shows the mean plasma amino acid profiles and fig 2 the mean urinary amino acid profiles set out in histogram form for both Down's children and controls. The error bars delineate $2 \times$ the standard error of the mean. Only where the error bars do not overlap is there statistical significance between the mean values. It can be clearly seen that only the plasma lysine concentrations achieve significance in the Down's syndrome group as compared to controls. Figure 3 shows plasma lysine concentrations in Down's patients and controls.

\section{Discussion}

Our results confirm Lejeune's finding only in respect of raised plasma concentrations of lysine in Down's syndrome. We did not

\section{York District Hospital, York \\ H J Heggarty \\ R Ball}

St James's University Hospital, Leeds M Smith

M J Henderson

Correspondence to: Dr H J Heggarty, Consultant Paediatrician, York Distric Yospital, Wiggin

Accepted 8 December 1995

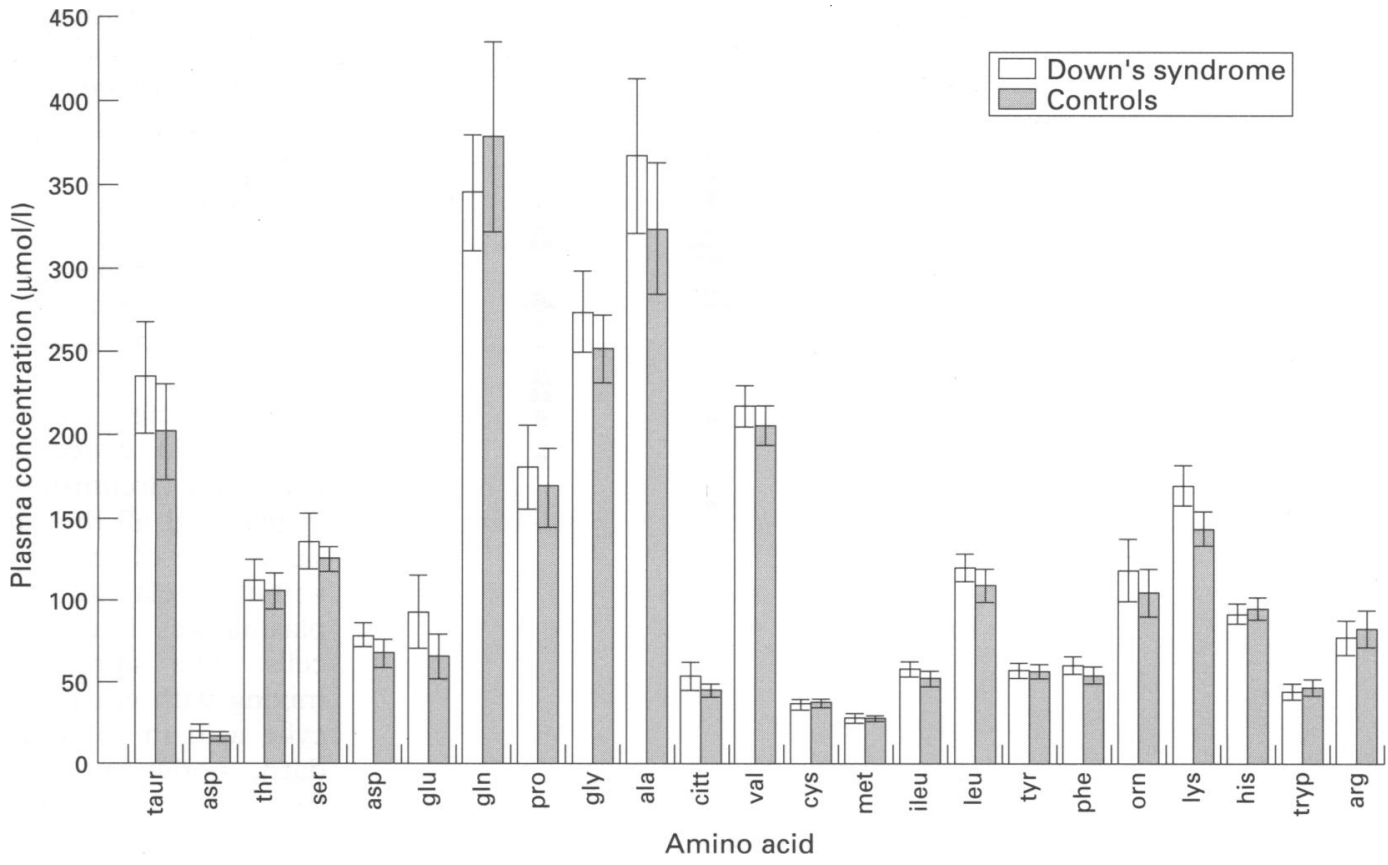

Figure 1 Plasma amino acids. 


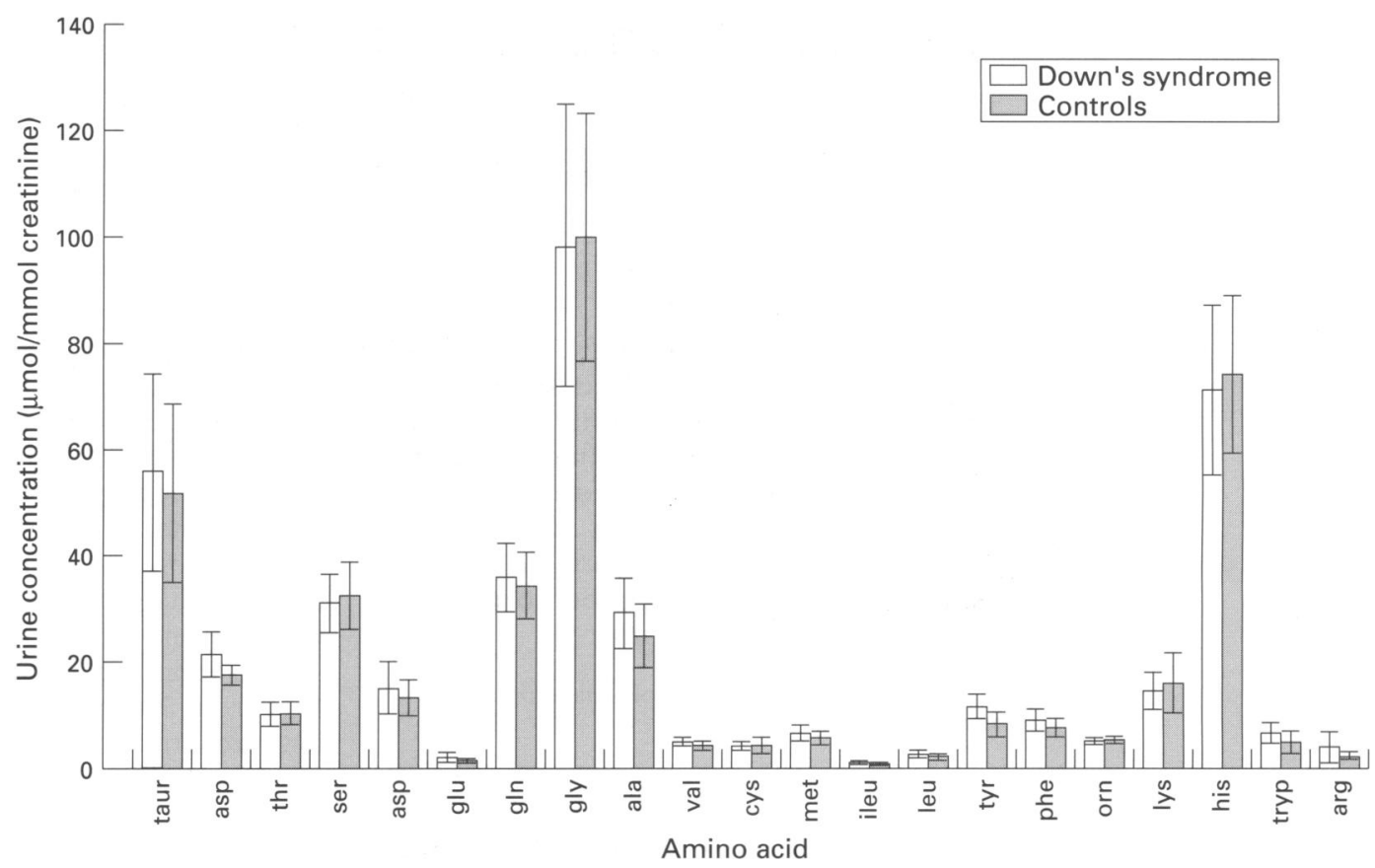

Figure 2 Urine amino acids.

Down's syndrome which they considered

confirm the other findings of his study, namely raised plasma cysteine, reduced plasma serine, and increased urinary tyrosine, methionine, methylhistidine, and cysteine. The urinary tyrosine in our Down's patients was considerably higher than in controls but the difference did not quite reach statistical significance.

In general, hyperlysinaemia is a benign disorder in which the serum lysine concentrations are usually much higher than those found in our Down's patients. We feel that the lysine levels in our Down's subjects are unlikely to have a significant clinical effect, though they may well indicate a metabolic pathway disequilibrium.

Lejeune and colleagues ${ }^{1}$ had found several different examples of 'enzyme imbalances' in

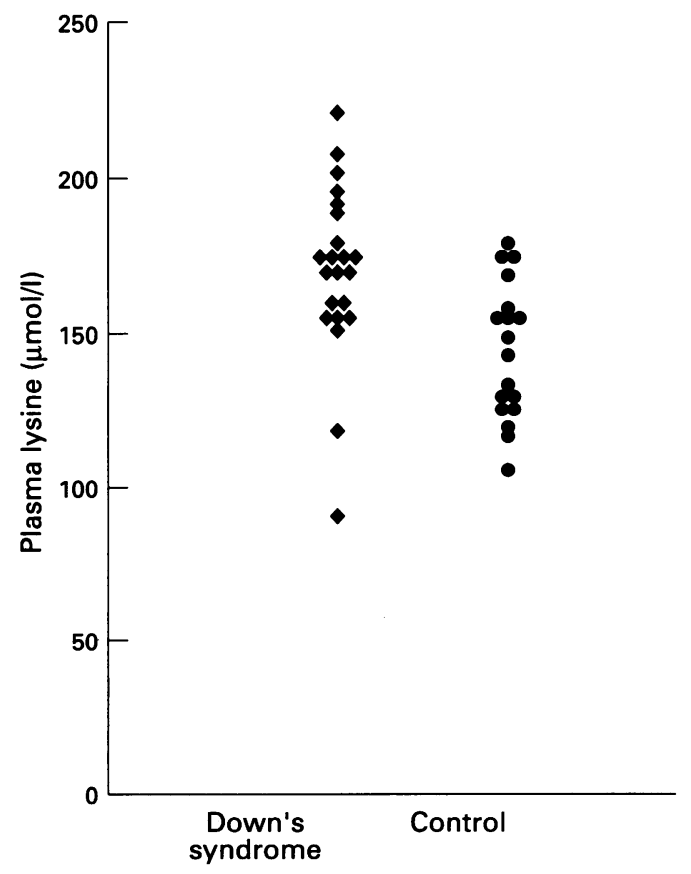

Figure 3 Plasma lysine. important. There are on chromosome 21 many genes which affect enzyme activity, for example, superoxide dismutase, cystathionine synthetase B, and those enzymes involved in purine metabolism and subthyroidism.

Peeters et $a l^{2}$ reported that some Down's subjects were particularly sensitive to 6-mercaptopurine and methotrexate (which involve folate metabolism).

Folinic acid therapy seemed to relieve psychoses in some Down's syndrome patients studied by Lejeune and his colleagues. ${ }^{3}$ Other workers in France plan to study the therapeutic affects of increasing serine intake in the diet plus folic acid supplements in Down's syndrome children. Lejeune's aims were to link the metabolic consequences of additional chromosomal material with a pathophysiological basis of mental retardation. His theory was that enzyme imbalance may be related to the primary chromosomal abnormality and that intellectual improvement could perhaps follow dietary correction of these biochemical imbalances.

Our study failed to confirm Lejeune's main findings. Perhaps children have a different amino acid profile from adults. Our subjects were all children, whereas his study contained adults.

We studied fasting plasma and urinary amino acid concentrations under very well controlled circumstances. All the children were fasting and all the samples were taken at the same time of the day. They were transferred without delay to the laboratory where the plasma was immediately separated from the cells. The samples were deproteinised by mixing with equal volumes of $5 \%$ sulphosalicylic acid in solution with the internal standard, norleucine. Supernatants were stored from collection to analysis in discrete, large batches. Lejeune's paper made no reference to the sample collection conditions. 
We did not include results for 3-methylhistidine excretion in the urine because this substance is not only a product of the catabolism of endogenous muscle but is also present in ingested meat. Therefore, unless subjects are on a meat-free diet the excretion is highly variable.

We conclude that when studied under carefully controlled conditions there are no differences in amino acid concentrations between control children and Down's patients that would justify dietary supplementation, as recommended by Professor Lejeune. We have preserved frozen samples from our study and perhaps they may be of value to other workers in this field.

We thank especially our patients, their parents and the staff of York District Hospital, the Biochemistry staff at York District York District Hospital, the Bochemistry staff at York District and St. James's Hospital, our secretaries, and the York Paediatric Charitable Trust Funds which supported this study. We are grateful too
for their advice.

1 Lejeune J, Rethore M-O, de Blois M-C, et al. Acidès amines et trisomie 21. Ann Genet 1992; 32: 8-13.

2 Peeters MA, Poon A, Zipursky A, Lejeune J. Toxicity of leukaemia therapy in children with Down's syndrome. Lancet 1986; ii: 1279 .

3 Lejeune J, Rethore M-O, de Blois M-C, et al. Métabolism des monocarbones et trisomie 21: sensibilité au methotrexate. Ann Genet 1989; 29: 16-19.

\section{Fungus through the very premature skin}

Systemic candidiasis in very low birthweight babies is well recognised. The route of infection has been thought to be either intravascular catheters or the gastrointestinal tract but a recent paper from Houston, Texas (Judith L Rowen and colleagues, Pediatrics 1995; 95: 682-7) suggests that in some babies the initial site of infection may be the skin.

Over a two year period (June 1991 to May 1993) 271 babies who weighed $1000 \mathrm{~g}$ or less at birth survived to age 6 days. Of these, $16(5.9 \%)$ developed invasive fungal dermatitis and 11 of the 16 had systemic fungal infection.

Invasive fungal dermatitis was characterised by ulceration of the skin and erosive lesions with extensive crusting and occurred at between 6 and 14 days of age.

Skin biopsy was performed on seven babies and showed fungal invasion of the skin in all seven with extension into the dermis in three. Of the 11 patients with evidence of systemic disease seven had fungus isolated from blood, four had fungal meningitis, two had urinary infection, and one peritonitis.

Candida albicans was the responsible organism in 11 patients. Other fungi grown were $C$ tropicalis, $C$ parapsilosis, Trichosporon beigelii, Aspergillus niger, Aspergillus fumigatus, and Curvularia species.

For each case three controls matched for hospital, date of admission, and birth weight were selected. Comparison of cases and controls showed that the babies with fungal disease were less mature (mean gestation $24.4 v 25.9$ weeks), more likely to have been born vaginally ( $81 \% v 50 \%$ ), more likely to have been given steroids $(81 \% v 46 \%)$, and had more hyperglycaemia.

The authors reemphasise the importance of meticulous skin care for very low birthweight babies and call for further research into improving skin barrier function. 